\title{
Quantitative PCR genotyping assay for the Ts65Dn mouse model of Down syndrome
}

\author{
Dong P. Liu, Cecilia Schmidt, Timothy Billings, and Muriel T. Davisson \\ The Jackson Laboratory, Bar Harbor, ME, USA
}

BioTechniques 35:1170-1180 (December 2003)

The Ts65Dn mouse is a segmentally trisomic model for Down syndrome. Until now, Ts65Dn mice have been identified by the laborious methods of either chromosomal analysis of cultured peripheral lymphocytes or fluorescent in situ hybridization (FISH). We report here a quantitative PCR method for genotyping Ts65Dn mice, as well as a phenotypic description for visually preclassifying mice to be genotyped.

\section{INTRODUCTION}

The Ts65Dn mouse was developed as a segmentally trisomic model for Down syndrome (DS) (1-4). Ts65Dn mice carry a small extra chromosome that contains the centromere and proximal end of mouse Chromosome 17 (about 5\%) and the distal telomere end of Chromosome 16 (about 20\%). The mice are trisomic for a Chromosome 16 segment extending from the gene encoding GA repeat binding protein, alpha (Gabpa) to the most distal gene encoding zinc finger protein 295 (Zfp295), representing about $60 \%$ of the known mouse orthologs of human Chromosome 21 genes $(5,6)$. Until recently, the standard method of genotyping for the Ts65Dn chromosome required peripheral lymphocyte culture and chromosome analysis (7), although fluorescent in situ hybridization (FISH) has been used in some laboratories $(8,9)$. Here we report a quantitative PCR method for genotyping Ts65Dn mice.

\section{MATERIALS AND METHODS}

Ts65Dn mice and their diploid littermates from the maintenance stock were used to develop a quantitative PCR assay. The Ts65Dn stock is maintained by mating trisomic Ts65Dn females to (C57BL/6JEi $\times$ C3H/HeSnJ) F1 hybrid males. Ts65Dn mice and diploid littermate controls were genotyped by cytological analysis (7), and coded DNA samples from the same mice were used for quantitative PCR analysis. Quantitative PCR results then were decoded, and the genotyping results were compared with those determined by cytological analysis.

\section{Sample Preparation}

Whole blood collected from either the retro-orbital sinus or the tail-tip (approximately 1 to $2 \mathrm{~mm} / \mathrm{sample}$ ) was used for real-time PCR analysis. Briefly, blood samples were digested with $100 \mathrm{ng} / \mathrm{mL}$ proteinase $\mathrm{K}$ for 1 h. After heat inactivation at $95^{\circ} \mathrm{C}$ for 5 min, samples were diluted with 10 $\mathrm{mM}$ Tris, $\mathrm{pH}$ 8.0, to approximately 0.1 $\mathrm{ng} / \mu \mathrm{L}$, based on an estimated yield of about $1.5 \mu \mathrm{g}$ DNA from $10 \mu \mathrm{L}$ of blood sample. An alkali method (10) was used for tail-tip samples, and similar results were obtained. Samples were neutralized and diluted with Tris, as in the protocol in Reference 10, to about $0.1 \mathrm{ng} / \mu \mathrm{L}$ based on an expected yield of approximately 1 to $2 \mu \mathrm{g}$ DNA from a 1- to 2 -mm tail sample.

\section{Real-Time Quantitative PCR}

We routinely use Primer Express ${ }^{\circledR}$ version 2.0 (Applied Biosystems, Foster City, CA, USA) to design TaqMan ${ }^{\circledR}$ primers (Applied Biosystems) and probes for quantitative PCR analysis. This software sets strict criteria in selecting primer and probe sequences such as amplicon size, melting temperature $\left(\mathrm{T}_{\mathrm{m}}\right)$, AT content, number of $\mathrm{C}$ verses $\mathrm{G}$ nucleotides in the probe sequence, no $\mathrm{G}$ at the $5^{\prime}$ end of the probe, etc. Occasionally the software fails to select optimal primers and probe for certain input sequences. So far we have designed more than 40 reactions without failure. For the Ts65Dn mice, we chose to use as markers the genes for amyloid $\beta$ (A4) precursor protein (App) and myxovirus (influenza virus) resistance $1(M x l)$, because they are close to the proximal and distal ends, respectively, of the Chromosome 16 segment in the trisomic chromosome. Our approach was to attempt to differentiate three copies of $A p p$ or $M x l$ in trisomic mice from two copies of App or Mxl in diploid controls using a quantitative PCR method. For the App gene (GenBank ${ }^{\circledR}$ accession no. U82624), TaqMan primers and probe were designed based on exon 17. The PCR product size is 78 bp. The sequences are: forward primer 5'-TGCTGAAGATGTGGGTTCGA3', reverse primer 5'-GACAATCACGGTTGCTATGACAA-3', and probe 5'-FAM-CAAAGGCGCCATCATCGGACTCA-TAMRA-3'. FAM is a fluorescent reporter and TAMRA is a quencher fluorophore. For Mxl (GenBank accession no. M21117), exon 14 sequence was used, and the PCR product size is $74 \mathrm{bp}$. The sequences for primers and probe are: forward primer 5'-TCTCCGATTAACCAGGCTAGCTAT-3', reverse primer 5'-GACATAAGGTTAGCAGCTAAAGGATCA- $3^{\prime}$, and probe $5^{\prime}$-FAM-TGGCTTTCCTGGTCGCTGTGCA-TAMRA-3'. The apolipoprotein B gene (Apob; GenBank accession no. X15191) was used as an internal control to normalize variations of the amount of input DNA. The product size is $73 \mathrm{bp}$. Here are the primer and probe sequences: forward primer 5'-CACGTGGGCTCCAGCATT-3', reverse primer $5^{\prime}$-TCACCAGTCATTTCTGCCTTTG- $3^{\prime}$, and probe $5^{\prime}$ VIC-CCAATGGTCGGGCACTGCTCAA-TAMRA-3'. VIC is a second fluorescent reporter.

The TaqMan probes for target genes App and Mxl and the control gene $A p o b$ were labeled with two different fluorescent reporters (FAM and VIC) so that a multiplexed PCR could be used. Doing a multiplexed reaction with an internal control (in this case Apob) avoids the need for determining DNA concentration and permits a relatively large range of variation in amount of template DNA. The PCR was set up as follows: $12.5 \mu \mathrm{L}$ of $2 \times$ TaqMan universal PCR master mix 
(Applied Biosystems), $0.25 \mu \mathrm{L}$ of each primer $(40 \mu \mathrm{M}), 0.75 \mu \mathrm{L}$ of each probe $(5 \mu \mathrm{M})$, and $10 \mu \mathrm{L}$ of diluted template DNA (about $0.1 \mathrm{ng} / \mu \mathrm{L}$ ). The reaction was carried out at $50^{\circ} \mathrm{C}$ for $2 \mathrm{~min}, 95^{\circ} \mathrm{C}$ for $10 \mathrm{~min}$, followed by 40 cycles of $95^{\circ} \mathrm{C}$ for $15 \mathrm{~s}$ and $60^{\circ} \mathrm{C}$ for $1 \mathrm{~min}$ on an ABI PRISM ${ }^{\circledR} 7000$ sequence detection system (Applied Biosystems) with a 96-well format. For each sample, triplicate PCRs were carried out.

\section{Analysis of Quantitative PCR Results}

After real-time PCRs, the average change $(\Delta)$ in cycle threshold (CT) of target gene App or $M x l$ from that of the internal control Apob was calculated $(\Delta \mathrm{CT}=\mathrm{CT}$ for App or $M x \mathrm{I}$ - CT for Apob) and analyzed. CT is defined as the PCR cycle at which an increase in reporter fluorescence above a baseline signal can first be detected. Routinely, we expect to see a CT for $A p o b$ at around 28 to 29, corresponding to about $1 \mathrm{ng}$ of input template DNA (Figure 1). For the ABI PRISM 7000 system, a few parameters, such as start and end cycles of base line and threshold for amplification plot, must be determined arbitrarily when doing a post-run analysis, which could affect the results. Routinely, we follow the guidelines of the instrument manual (e.g., we use 2 as a default for starting cycle and end cycle approximately 5 cycles before amplification starts). Where the threshold for the amplification plot is set could influence absolute quantitation for transgene copy number determination and mRNA expression level dramatically, but is much less likely to affect relative quantitation, such as determining homozygous versus hemizygous transgenic mice or distinguishing three versus two copies of a gene as we are trying to do. In addition, we have an objective rather than an arbitrary standard in setting the threshold for amplification for this specific situation. We take advantage of the fact that diploid samples have the same copy numbers (two copies) of both the target gene (App or $M x l$ ) and the internal control gene (Apob). Therefore, the threshold is first placed above the noise to the linear part of the amplification curve. Fine adjustment is achieved by moving the threshold up or down until the average $\Delta \mathrm{CT}$ is close to 0 for one group of samples (diploid samples). If both diploid and trisomic samples are present during the reaction, two distinguishable groups should be observed, one with an average $\Delta \mathrm{CT}$

close to 0 , and the second with an average $\Delta \mathrm{CT}$ close to -0.6 (trisomic samples). Anything less obvious would suggest a failure, and the whole experiment would need to be repeated.

For each PCR experiment, we included a standard curve. These were done by using four 1:2 serial dilutions over a range of 8 -fold for one sample, including a dilution of about $0.1 \mathrm{ng} / \mu \mathrm{L}$ DNA (Figure 1). The $\Delta \mathrm{CT}$ over this range should remain the same, and the CT for Apob (reflects the amount of template DNA) for all other test samples also should fall within this range. Because the Ts65Dn mouse has three copies of the App and $M x l$ genes, the expected difference between the $\Delta \mathrm{CT}$ for Ts65Dn mice and the $\Delta \mathrm{CT}$ for diploid control mice should be 0.585 $\left(2^{0.585}=1.5\right.$, where 1.5 is the fold difference between three copies of App in trisomic mice versus two copies in wild-type mice).

\section{Statistical Analysis}

A clustering method called k-means (11) was used to test whether 2 groups of $\Delta \mathrm{CT}$ are appropriate to cluster all samples that are a mixture of two different populations (diploid and trisomy) for App and $M x l$, respectively. After partitioning all samples into two different populations (see Results section), the average $\Delta \mathrm{CT}$ from the two populations were compared with each other to determine whether the two groups were significantly different. For each group, either diploid or trisomy, $\triangle \mathrm{CT}$ for $A p p$ and $M x l$ were then pooled and used to determine the $95 \%$ confidence interval, which then was used as criteria to genotype whether a given sample belongs to diploid or trisomic mice.

\section{RESULTS AND DISCUSSION}

Quantitative PCR has been used successfully to determine zygosity of transgenic mice (12), where a 2 -fold difference of transgene copy insert number between hemizygous and homozygous mice is expected. This translates to one cycle difference in terms of $\Delta \mathrm{CT}$. Our experiments addressed the question: is this the limit one can get

Figure 1. Two standard curves from two separate experiments. A diploid sample (A) and a trisomy sample (B) were used for quantitative PCR. Diamonds represent Apob internal control, and squares represent App. Ordinate units are log scale of estimated amount of template DNA. Abscissa units are the cycle threshold (CT). Similar slope of the curves indicates similar amplification efficiency, with a correlation index of $>0.99$ for each curve. Over an 8 -fold dilution range (corresponding to roughly 2 to 0.25 ng of template DNA), the delta ( $\Delta$; average change) CT remained constant ( 0 for the diploid sample and -0.58 for the trisomy sample). 
with this method?

To answer this question, quantitative PCR was used to see if it could reliably differentiate trisomic mice from diploid mice in the trisomic model for Down syndrome. Ninety-four mice, including Ts65Dn mice and their diploid littermates from the Ts65Dn colony, were typed by quantitative PCR for both the $A p p$ and $M x l$ genes. For 75 of the mice, these results were compared with results determined by the cytological method. Table 1 summarizes the results. $\triangle \mathrm{CT}$ for $A p p$ and $M x l$ was then used by the kmeans clustering method to determine whether two groups give an appropriate separation for all samples. K-means clustering results with 2 clusters for all samples from both App and Mxl are presented in Figure 2. A clear separation is present in this plot. The difference with respect to $\Delta \mathrm{CT}$ between the two separated populations is strongly significant $(P<0.0001)$. As a comparison, clustering all samples into three, four, or five groups was attempted, but none of these give a clear separation for all samples (results not shown). The average $\triangle \mathrm{CT}$ for these two groups is -0.0196 (diploid) and -0.5459 (trisomy), respectively. Using these data, we further determined the $95 \%$ confidence interval for diploid mice to be -0.1958 to 0.1565 and for trisomic mice to be -0.7259 to -0.3660 . When applying these criteria to the $\Delta \mathrm{CT}$ values in Table 1, we can determine the majority of the samples as either diploid $(+)$ or trisomic (Ts), with few exceptions (marked as + ?, Ts? or ?). For example, 92 of 94 samples can be assigned based on $\Delta \mathrm{CT}$ of App quantitative PCR, and 85 of 94 samples can be assigned based on $\Delta \mathrm{CT}$ of $M x I$ quantitative PCR. Eight of the
Table 1. Comparison of Genotyping Results by Quantitative PCR and Cytological Methods

\begin{tabular}{|c|c|c|c|c|c|c|c|}
\hline Sample & $\begin{array}{l}\text { Average } \\
\Delta \mathrm{CT} \text { App }\end{array}$ & $\begin{array}{l}\text { Standard } \\
\text { Deviation }\end{array}$ & $\begin{array}{c}\text { Genotype } \\
\text { by App }\end{array}$ & $\begin{array}{c}\text { Average } \\
\Delta \mathrm{CT} M \times 1\end{array}$ & $\begin{array}{l}\text { Standard } \\
\text { Deviation }\end{array}$ & $\begin{array}{c}\text { Genotype } \\
\text { by } M \times 1\end{array}$ & $\begin{array}{l}\text { Genotype } \\
\text { by Culture }\end{array}$ \\
\hline 1 & -0.09 & 0.03 & + & 0.12 & 0.04 & + & not cultured \\
\hline 2 & -0.62 & 0.14 & Ts & -0.55 & 0.03 & Ts & not cultured \\
\hline 3 & -0.06 & 0.12 & + & 0.11 & 0.07 & + & not cultured \\
\hline 4 & -0.02 & 0.13 & + & 0.26 & 0.15 & $+?$ & not cultured \\
\hline $4^{*}$ & & & & -0.09 & 0.01 & + & \\
\hline 5 & -0.03 & 0.05 & + & 0.28 & 0.10 & $+?$ & not cultured \\
\hline $5^{*}$ & & & & 0.12 & 0.10 & + & \\
\hline 6 & -0.68 & 0.03 & Ts & -0.41 & 0.05 & Ts & not cultured \\
\hline 7 & -0.01 & 0.04 & + & -0.01 & 0.08 & + & not cultured \\
\hline 8 & -0.06 & 0.02 & + & -0.04 & 0.01 & + & + \\
\hline 9 & -0.04 & 0.05 & + & -0.20 & 0.12 & $+?$ & + \\
\hline $9^{*}$ & & & & -0.06 & 0.03 & + & \\
\hline 10 & -0.61 & 0.15 & Ts & -0.60 & 0.02 & Ts & Ts \\
\hline 11 & 0 & 0.06 & + & -0.05 & 0.07 & + & + \\
\hline 12 & -0.51 & 0.02 & Ts & -0.56 & 0.04 & Ts & Ts \\
\hline 13 & -0.07 & 0.11 & + & -0.04 & 0.06 & + & + \\
\hline 14 & -0.05 & 0.05 & + & -0.09 & 0.13 & + & + \\
\hline 15 & -0.53 & 0.10 & Ts & -0.57 & 0.17 & Ts & Ts \\
\hline 16 & 0.11 & 0.15 & + & -0.05 & 0.08 & + & + \\
\hline 17 & -0.07 & 0.12 & + & -0.04 & 0.04 & + & + \\
\hline 18 & -0.11 & 0.05 & + & -0.04 & 0.06 & + & + \\
\hline 19 & -0.05 & 0.05 & + & -0.02 & 0.02 & + & retest \\
\hline 20 & 0.05 & 0.16 & + & 0.02 & 0.17 & + & + \\
\hline 21 & -0.01 & 0.04 & + & -0.05 & 0.02 & + & + \\
\hline 22 & -0.65 & 0.05 & Ts & -0.66 & 0.08 & Ts & Ts \\
\hline 23 & -0.47 & 0.02 & Ts & -0.56 & 0.08 & Ts & Ts \\
\hline 24 & 0.01 & 0.04 & + & 0.04 & 0.07 & + & + \\
\hline 25 & -0.02 & 0.09 & + & 0.02 & 0.18 & + & retest \\
\hline 26 & -0.10 & 0.06 & + & -0.19 & 0.09 & + & + \\
\hline 27 & -0.12 & 0.07 & + & -0.08 & 0.02 & + & + \\
\hline 28 & -0.08 & 0.01 & + & -0.02 & 0.05 & + & + \\
\hline 29 & -0.02 & 0.12 & + & -0.10 & 0.13 & + & + \\
\hline 30 & -0.07 & 0.04 & + & -0.19 & 0.04 & + & + \\
\hline 31 & -0.41 & 0.06 & Ts & -0.43 & 0.08 & Ts & Ts \\
\hline 32 & -0.50 & 0.14 & Ts & -0.57 & 0.03 & Ts & Ts \\
\hline 33 & 0.01 & 0.07 & + & -0.11 & 0.09 & + & not cultured \\
\hline 34 & 0.03 & 0.04 & + & -0.06 & 0.06 & + & + \\
\hline 35 & -0.44 & 0.05 & Ts & -0.54 & 0.09 & Ts & Ts \\
\hline 36 & 0.01 & 0.05 & + & -0.10 & 0.02 & + & not cultured \\
\hline 37 & 0.01 & 0.08 & + & -0.12 & 0.12 & + & + \\
\hline 38 & -0.53 & 0.06 & Ts & -0.64 & 0.10 & Ts & Ts \\
\hline 39 & -0.51 & 0.09 & Ts & -0.51 & 0.17 & Ts & Ts \\
\hline 40 & -0.05 & 0.05 & + & -0.03 & 0.10 & + & + \\
\hline 41 & -0.06 & 0.08 & + & -0.01 & 0.02 & + & $\begin{array}{c}+ \\
\text { continued }\end{array}$ \\
\hline
\end{tabular}


Table 1. Continued.

\begin{tabular}{|c|c|c|c|c|c|c|c|}
\hline Sample & $\begin{array}{l}\text { Average } \\
\Delta \mathrm{CT} \text { App }\end{array}$ & $\begin{array}{l}\text { Standard } \\
\text { Deviation }\end{array}$ & $\begin{array}{c}\text { Genotype } \\
\text { by App }\end{array}$ & $\begin{array}{l}\text { Average } \\
\Delta \mathrm{CT} M x 1\end{array}$ & $\begin{array}{l}\text { Standard } \\
\text { Deviation }\end{array}$ & $\begin{array}{c}\text { Genotype } \\
\text { by } M \times 1\end{array}$ & $\begin{array}{l}\text { Genotype } \\
\text { by Culture }\end{array}$ \\
\hline 42 & -0.50 & 0.09 & Ts & -0.56 & 0.05 & Ts & Ts \\
\hline 43 & 0.01 & 0.02 & + & 0.16 & 0.08 & + & + \\
\hline 44 & -0.21 & 0.04 & $+?$ & 0.01 & 0.03 & + & + \\
\hline 45 & 0.01 & 0.02 & + & -0.02 & 0.06 & + & + \\
\hline 46 & 0.06 & 0.07 & + & -0.02 & 0.09 & + & + \\
\hline 47 & 0.02 & 0.04 & + & 0.08 & 0.06 & + & + \\
\hline 48 & 0.05 & 0.08 & + & -0.13 & 0.12 & + & + \\
\hline 49 & 0.04 & 0.12 & + & 0.63 & 1.33 & $?$ & + \\
\hline $49^{*}$ & & & & -0.08 & 0.08 & + & \\
\hline 50 & 0 & 0.09 & + & -0.05 & 0.04 & + & + \\
\hline 51 & 0 & 0.08 & + & -0.05 & 0.05 & + & + \\
\hline 52 & -0.60 & 0.04 & Ts & -0.75 & 0.05 & Ts? & Ts \\
\hline $52^{*}$ & & & & -0.57 & 0.05 & Ts & \\
\hline 53 & -0.57 & 0.10 & Ts & -0.61 & 0.02 & Ts & Ts \\
\hline 54 & 0.01 & 0.15 & + & -0.14 & 0.04 & + & + \\
\hline 55 & -0.06 & 0.09 & + & 0.02 & 0.11 & + & + \\
\hline 56 & -0.49 & 0.06 & Ts & -0.74 & 0.04 & Ts? & Ts \\
\hline $56^{\star}$ & & & & -0.43 & 0.04 & Ts & \\
\hline 57 & 0.05 & 0.03 & + & -0.15 & 0.08 & + & + \\
\hline 58 & -0.50 & 0.08 & Ts & -0.48 & 0.10 & Ts & retest \\
\hline 59 & -0.03 & 0.10 & + & -0.17 & 0.04 & + & + \\
\hline 60 & -0.53 & 0.05 & Ts & -0.68 & 0.03 & Ts & Ts \\
\hline 61 & -0.51 & 0.07 & Ts & -0.51 & 0.13 & Ts & Ts \\
\hline 62 & -0.53 & 0.09 & Ts & -0.45 & 0.07 & Ts & Ts \\
\hline 63 & -0.17 & 0.07 & + & 0.15 & 0.05 & + & + \\
\hline 64 & -0.42 & 0.08 & Ts & -0.30 & 0.05 & Ts? & Ts \\
\hline $64^{*}$ & & & & -0.55 & 0.05 & Ts & \\
\hline 65 & -0.52 & 0.06 & Ts & -0.42 & 0.07 & Ts & Ts \\
\hline 66 & -0.02 & 0.05 & + & 0.12 & 0.10 & + & + \\
\hline 67 & -0.63 & 0.05 & Ts & -0.51 & 0.07 & Ts & Ts \\
\hline 68 & -0.45 & 0.14 & Ts & -0.60 & 0.03 & Ts & Ts \\
\hline 69 & -0.62 & 0.10 & Ts & -0.52 & 0.07 & Ts & Ts \\
\hline 70 & -0.54 & 0.09 & Ts & -0.39 & 0.07 & Ts & Ts \\
\hline 71 & -0.65 & 0.13 & Ts & -0.50 & 0.09 & Ts & Ts \\
\hline 72 & -0.47 & 0.26 & Ts? & -0.54 & 0.03 & Ts & Ts \\
\hline 73 & -0.56 & 0.08 & Ts & -0.49 & 0.15 & Ts & Ts \\
\hline 74 & -0.18 & 0.08 & + & -0.01 & 0.12 & + & + \\
\hline 75 & -0.67 & 0.03 & Ts & -0.42 & 0.03 & Ts & Ts \\
\hline 76 & -0.07 & 0.03 & + & 0.07 & 0.05 & + & + \\
\hline 77 & 0.04 & 0.15 & + & 0.14 & 0.04 & + & + \\
\hline 78 & -0.05 & 0.13 & + & 0.17 & 0.02 & $+?$ & not cultured \\
\hline $78^{*}$ & & & & -0.12 & 0.06 & + & \\
\hline 79 & -0.14 & 0.11 & + & 0.11 & 0.20 & + & not cultured \\
\hline 80 & -0.02 & 0.07 & + & 0.03 & 0.06 & + & $\begin{array}{c}\text { not cultured } \\
\text { continued }\end{array}$ \\
\hline
\end{tabular}

nine samples typed for $M x I$ clustered with one genotype or the other but were slightly outside the $95 \%$ confidence limit. The retest results for these eight samples confirmed the original probable genotype (Table 1). The ninth sample (no. 49) could not be classified in either genotype group initially. Retest placed it within the range for one genotype, a result which was confirmed by cytological typing. The repeat results for the two probable samples (nos. 44 and 72) for App quantitative PCR, however, were still ambiguous due to large standard deviation or no amplification, which was probably a result of the poor quality of the two DNA samples. Most importantly, all genotyping results based on either App or $M x l$ are consistent with those determined by cytological methods $(n=75)$ (Table 1$)$.

Using the above criteria, we tested an additional 68 mice, including Ts65Dn mice and their diploid littermates from the Ts65Dn colony, using App quantitative PCR and cytological methods. We choose App quantitative PCR instead of Mxl quantitative PCR because it seems to give more consistent results. Results from a typical experiment are shown in Figure 3. The results were $100 \%$ concordant for 64 of the 68 mice genotyped by both methods. Quantitative PCR results for the remaining four samples (approximately 6\%) were inconclusive, because either the standard error bar was too large or they fell out of the 95\% confidence interval (see sample no. 5 in Figure 3). Repeating the quantitative PCR analysis with the same sample preparation placed them in one of the two clusters. For example, sample no. 5 in Figure 3 fell in the Ts65Dn cluster of samples when rean- 
alyzed, which was consistent with the genotyping results by cytological analysis. If such samples are still inconclusive after repeating the quantitative PCR analysis, resampling of original mice is recommended. The few samples that fell within a cluster but had large standard errors never moved to the other genotype cluster when repeated. The difference between the average $\Delta \mathrm{CT}$ of Ts65Dn mice and the average $\Delta \mathrm{CT}$ of diploid littermates is 0.51 , close to the expected difference of 0.585 . An additional 30 Ts65Dn breeder females typed by quantitative PCR were confirmed by producing Ts65Dn progeny.

We believe that our data firmly establish for the first time that quantitative PCR can be used to differentiate a 1.5fold difference (two versus three copies) of a gene, using Ts65Dn mice as a model, therefore further expanding the application of this technique. This is obviously more sensitive and reliable than and preferable to other DNA-based methods, such as Southern blot analysis, since no extensive purification and accurate quantification of genomic DNA is required. For genotyping of Ts65Dn mice, the quantitative PCR method has two major advantages over the previously used cytological methods (7-9). First, it is much less labor-intensive. It requires about $4 \mathrm{~h}$ (1.5 of which are machine run time) rather than the 2 to 3 days required for the method of culturing cells and chromosome analysis (7). The interphase FISH methods $(8,9)$ require less time than culture and chromosome analysis, but still take longer and are more labor-intensive than this quantitative PCR method. Although the quantitative PCR reagents may be slightly more expensive than those used in the other methods, we find the savings in labor more than offset this cost. Second, the quantitative PCR method can be used to genotype mice at any age including embryos (as can the FISH methods), whereas the chromosomal method is difficult to use in mice younger than 6 to 7 weeks of age, because peripheral lymphocyte culture depends on sufficient maturation of the immune system for the lymphocytes to proliferate in response to mitogens. This quantitative PCR DNA typing method also should make genotyping of Ts65Dn mice more accessible for most researchers, who are less likely to be doing FISH or chromosome analysis already in their laboratories and may have access to core services that do real-time quantitative PCR.

The incidence of trisomy among progeny is only $19 \%-25 \%$. To streamline the typing process further, the animals may be visually phenotyped before they are genotyped. The phenotype is variable and subtle, but to the trained eye the trisomic mice can be identified tentatively. Ts65Dn mice are usually smaller than their control littermates at weaning. When one lifts the cage cover slowly, the trisomic

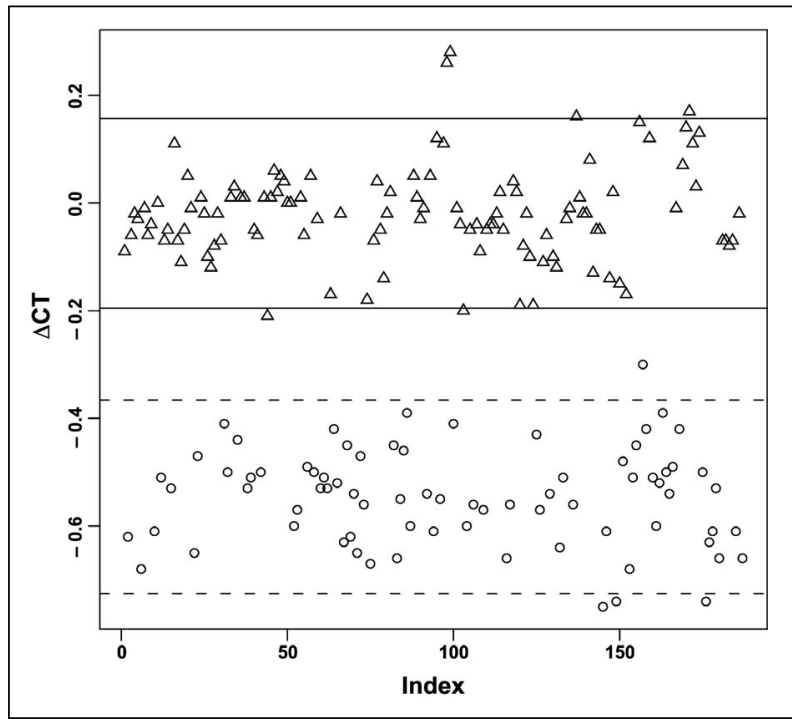

Figure 2. Statistical analysis by k-means method of data from Table 1. Each symbol (triangle or circle) represents one sample. This method clearly demonstrates that there are two clusters of samples, one group around $\Delta \mathrm{CT}$ of 0 (diploid samples, represented by triangle symbol) and another group around -0.5 (trisomy samples, represented by circle symbol). $95 \%$ confidence interval is outlined by parallel lines. $\Delta$, average change; CT, cycle threshold. 


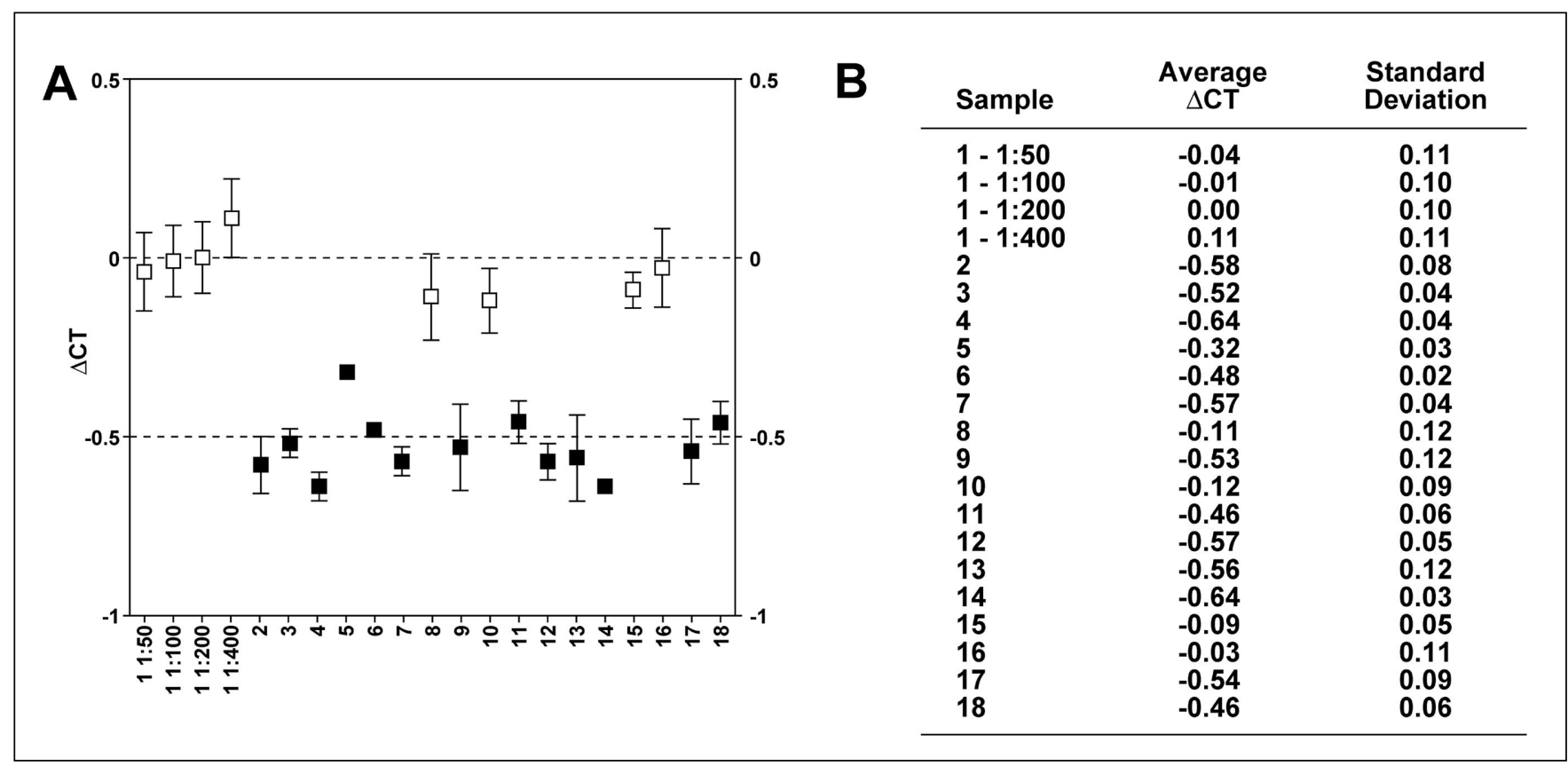

Figure 3. Results of a typical experiment. (A) Two groups of samples can be clearly identified: (i) diploid samples (open squares) have $\Delta$ CT close to 0 and (ii) trisomy samples (filled squares) have $\Delta \mathrm{CT}$ close to -0.5. The first four samples are different dilutions of a diploid sample run as a control. Sample no. 5 (not no. 5 shown in Table 1 ) had a $\Delta \mathrm{CT}$ of -0.32 . When reanalyzed, it had a $\Delta \mathrm{CT}$ close to -0.5 and was subsequently shown by chromosomal analysis to be Ts65Dn. (B) Actual $\Delta \mathrm{CT}$ and standard deviation for each sample. $\Delta$, average change; CT, cycle threshold.

mice often raise their heads and bring their ears to the sides of the head. When picked up by the tail, some trisomic mice make a high-pitched continuous squeak. Ts65Dn mice often display stereotypic behavior, repeatedly jumping up and down by the side of the cage. Finally, when a pencil is placed vertically in front of the mouse, controls will run around it but Ts65Dn mice sit back on their haunches and "chatter." Phenotyping the mice is not $100 \%$ accurate nor should it be relied upon to classify mice, but it does help eliminate control animals that are not needed and reduce the number of mice that must be genotyped. This pretyping by phenotype is unlikely to have put selection pressure on the trisomic phenotype for three reasons. First, we initially typed all mice cytologically, and the frequency of trisomic mice $(19 \%-25 \%)$ was the same as what we see now. Second, the genetic background is remixed at each generation by outcrossing Ts65Dn mice to the F1 hybrid. Third, in nearly 20 years of maintaining the stock, the genotyping by culture has been $>99 \%$ concordant with the phenotype. Occasionally a small mouse will turn out to be a wild-type runt, but we have almost never found a wild-type-appearing mouse that genotyped as a trisomic mouse. The visual and genotypic classification of the 143 mice in this report was $100 \%$ concordant. The combination of visual phenotyping followed by quantitative PCR genotyping should make identifying Ts65Dn mice easier than chromosomal or FISH analysis for most researchers.

\section{ACKNOWLEDGMENTS}

We thank Linda L. Washburn and Michael V. Wiles for reading the manuscript prior to submission and Weidong Zhang for help with statistical analysis. This work was supported by grants HD73265 from the National Institute of Child Health and Human Development and RR07981 from the National Center for Research Resources.

\section{REFERENCES}

1. Davisson, M.T., C. Schmidt, and E.C. Akeson. 1990. Segmental trisomy of murine Chromosome 16: a new model system for studying Down syndrome, p. 263-280. In D. Patterson and C.J. Epstein (Eds.), Molecular
Genetics of Chromosome 21 and Down Syndrome. Progress in Clinical and Biological Research, vol. 360. Wiley-Liss, New York.

2. Davisson, M.T., C. Schmidt, R.H. Reeves, N.G. Irving, E.C. Akeson, B.S. Harris, and R.T. Bronson. 1993. Segmental trisomy as a model for Down syndrome and other aneuploid conditions, p. 117-133. In C.J. Epstein (Ed.), The Phenotypic Mapping of Down Syndrome and Other Aneuploid Conditions. Progress in Clinical and Biological Research, vol. 384. Wiley-Liss, New York.

3. Davisson, M.T. and A.C.S. Costa. 1999 Mouse models of Down syndrome, p. 297 327. In B. Popko (Ed.), Mouse Models in the Study of Genetic Neurological Disorders. Advances in Neurochemistry, vol. 9. Kluwer Academic/Plenum, New York.

4. Reeves, R.H., N.G. Irving, T. Moran, A. Wohn, S.S. Sissodia, C. Schmidt, and M.T. Davisson. 1995. A mouse model for Down syndrome exhibits learning and behavior deficits. Nat. Genet. 11:177-184.

5. Akeson, E.C., J.P. Lambert, S. Narayanswami, K. Gardiner, L.J. Bechtel, and M.T. Davisson. 2001. Ts65Dn-localization of the translocation breakpoint and trisomic gene content in a mouse model for Down syndrome. Cytogenet. Cell Genet. 93:270-276.

6. Davisson, M.T., L.J. Bechtel, E.C. Akeson, A. Fortna, D. Slavov, and K. Gardiner. 2001. Evolutionary breakpoints on human chromosome 21. Genomics 78:99-106.

7. Davisson, M.T. and E.C. Akeson. 1987. An improved method for preparing G-banded chromosomes from mouse peripheral blood. Cytogenet. Cell Genet. 45:70-74.

8. Strovel, J., J. Stamberg, and P.J. Yarowsky. 
1999. Interphase FISH for rapid identification of a Down syndrome animal model. Cytogenet. Cell Genet. 86:285-287.

9. Korenberg, J.R., X.N. Chen, K.L. Devon, D. Noya, M.L. Oster-Granite, and B.W. Birren. 1999. Mouse molecular cytogenetic resource: 157 BACs link the chromosomal and genetic maps. Genome Res. 9:514-523.

10. Truett, G.E., P. Heeger, R.L. Mynatt, A.A. Truett, J.A. Walker, and M.L. Warman. 2000. Preparation of PCR-quality mouse genomic DNA with hot sodium hydroxide and tris (HotSHOT). BioTechniques 29:52-54.

11. Hartigan, J.A. and M.A. Wong. 1979. A K-means clustering algorithm. Appl. Stat. 28: 100-108.

12. Tesson, L., J.M. Heslan, S. Menoret, and I. Anegon. 2002. Rapid and accurate determination of zygosity in transgenic animals by real-time quantitative PCR. Transgenic Res. 11:43-48.

Received 8 May 2003; accepted 22 October 2003.

Address correspondence to Muriel T. Davisson, The Jackson Laboratory, 600 Main Street, Bar Harbor, ME 04609, USA. e-mail:mtd@jax.org

\title{
Annealing control primer system for improving specificity of PCR amplification
}

\author{
In-Taek Hwang, Yun-Jee Kim, Seung-Hyun Kim, Chae-II Kwak, \\ Young-Yun Gu, and Jong-Yoon Chun \\ Seegene Life Science Laboratory, Seoul, South Korea
}

BioTechniques 35:1180-1184 (December 2003)

A novel primer designed to improve the specificity of PCR amplification, called the annealing control primer (ACP), comprises a tripartite structure with a polydeoxyinosine [poly $(d I)]$ linker between the $3^{\prime}$ end target core sequence and the $5^{\prime}$ end nontarget universal sequence. We show that this ACP linker prevents annealing of the $5^{\prime}$ end nontarget sequence to the template and facilitates primer hybridization at the $3^{\prime}$ end to the target sequence at specific temperatures, resulting in a dramatic improvement of annealing specificity. The effect of this linker is demonstrated by the incorporation of ACP sequences as primers during the amplification of target nucleotide sequence and as hybridization probes in the genotyping of single nucleotide polymorphisms. This is the first report to show that a poly(dI) linker between two different sequences of ACP forms a bubble-like structure and disrupts or destabilizes DNA duplex formation at certain annealing temperatures.

\section{INTRODUCTION}

The success of PCR amplification relies solely on the specificity with which a primer anneals to its target sequences. Therefore, it is important to optimize this molecular interaction (1). The annealing temperature is critical for determining whether a primer binds only to its perfect complement or to sequences with one or more mismatches. By adjusting the annealing temperature, one can alter the specificity of pairing between template and primer. Numerous approaches have been introduced to increase primer annealing specificity. Longer primers with universal, homopolymer, or loop sequence tails at their $5^{\prime}$ ends improve the specificity of PCR amplification and the stability of hybridization (2-4). However, this approach does not abrogate nonspecific hybridization resulting from the involvement of the tail or loop sequence in the priming reaction. This limitation of longer primers necessitates the specification of the annealing sequences of the primers to exclude nonspecific annealing. Here we describe a novel annealing control primer (ACP) that specifically targets sequence hybridization to the template via a polydeoxyinosine [poly $(\mathrm{dI})]$ linker. The structure of ACP comprises (i) a $3^{\prime}$ end region with a target core nucleotide sequence that substantially complements the template nucleic acid for hybridization; (ii) a $5^{\prime}$ end region with a nontarget universal nucleotide sequence; and (iii) a poly(dI) linker bridging the $3^{\prime}$ and $5^{\prime}$ end sequences.

\section{Rationale of Annealing Control Primer Oligonucleotides}

The presence of universal bases in a primer, such as deoxyinosine $(5,6)$, 1 -( $2^{\prime}$-deoxy- $\beta$-D-ribofuranosyl)-3-nitropyrrole (7), and 5-nitroindole (8), leads to low annealing temperatures due to weaker hydrogen bonding interaction in base pairing. In this study, we show that the presence of a poly(dI) linker between the $3^{\prime}$ end and $5^{\prime}$ end sequences of a primer generates a region with a lower melting temperature $\left(\mathrm{T}_{\mathrm{m}}\right)$ via the formation of a bubble-like structure at specific temperatures. The poly(dI) linker in the bubble-like structure affects the annealing of each region of the primer. Essentially, the ACP linker prevents the $5^{\prime}$ region from annealing under conditions in which the target $3^{\prime}$ sequence anneals to the template at the original annealing temperature. 